\title{
Tecnologias de informação e comunicação: novas sociabilidades nas bibliotecas universitárias
}

\author{
Valdir José Morigi \\ Professor adjunto II do Departamento de Ciências da Informação, \\ Fabico/UfRGS. Professor do Programa de Pós-Graduação em \\ Comunicação e Informação. Doutor em sociologia, FFLCH/USP. \\ E-mail:valdir.morigi@ufrgs.br

\section{Cleusa Pavan} \\ Graduanda do Curso de Biblioteconomia, Fabico/UFRGS \\ Bolsista de Iniciação Científica/Propesq. \\ E-mail: cleusapavan@yahoo.com.br
}

\section{Resumo}

A utilização das tecnologias de informação e comunicação na vida cotidiana criou novas formas de interação entre as pessoas, que implicam o redimensionamento das funções e dos papéis sociais. O objetivo deste estudo foi verificar como são percebidas as novas formas de sociabilidade pelos bibliotecários e analisar, nas relações entre tais profissionais e os usuários, as mudanças decorrentes do emprego das tecnologias de informação e comunicação. Os dados foram obtidos em entrevistas com profissionais das bibliotecas universitárias públicas e privadas de Porto Alegre-RS. Concluiuse que os bibliotecários percebem claramente as novas formas de sociabilidade no seu ambiente de trabalho, considerando a tecnologia um fator de interferência na relação com os usuários. Outro elemento identificado foi a existência de zonas de conflito introduzidas pela mediação das tecnologias de informação e comunicação nas bibliotecas universitárias, comuns no jogo da sociabilidade.

\section{Palavras-chave}

Bibliotecas universitárias; Sociabilidade; Novas sociabilidades; Práticas profissionais; Tecnologias de informação e comunicação.

Technologies of information and communication: new forms of sociability in the university libraries

\begin{abstract}
The use of new communication and information technologies in daily life has created new forms of interaction between people. These new forms of sociability cause changes on both the functions and social roles. In this study, the goal was to verify how those new forms of sociability, which are influenced by the use of new technologies are perceived by librarians and to analyze the changes in relationship between such professionals and library users. The data was obtained from interviews with librarians from both public and private university libraries in the city of Porto Alegre-RS. The conclusions include the notion that librarians do clearly perceive those new forms of sociability in their workplace, regarding technology as a factor that influences the relationship with users. Also, the existence of conflict zones, brought by the mediation of communication and information technologies in university libraries, has been identified.
\end{abstract}

\section{Keywords}

University libraries; Sociability; New sociabilities; Professional practices; Communication and information technologies.

\section{O CENÁRIO}

É inegável que, hoje, estamos passando por um processo de mudança em todas as áreas da sociedade. $\mathrm{O}$ impacto das tecnologias de informação e comunicação (TICs) é sentido sobre toda a vida social, seja no trabalho, no lazer e nas relações entre os indivíduos, principalmente na maneira com que se comunicam.

A utilização de tais tecnologias cria e recria novas formas de interação, novas identidades, novos hábitos sociais, enfim, novas formas de sociabilidade. As relações sociais já não ocorrem, necessariamente, pelo contato face a face entre os indivíduos. Elas passaram a ser mediadas pelo computador, independentes de espaço e tempo definidos. Informação e conhecimento tornaram-se variáveis imprescindiveis para o cidadão neste novo tempo que se estabelece, denominado das mais variadas formas, como era da informação, sociedade pósindustrial, era do virtual ou sociedade da informação e do conhecimento.

Eisenberg \& Cepik (2002) descrevem a sociedade da informação em três frentes gerais: uma economia baseada no conhecimento, um novo papel das finanças e uma sociabilidade em rede. Conforme os autores, esta última se expressa tanto na esfera do consumo quanto na circulação de produtos em escala mundial, ultrapassando as fronteiras territoriais. A nova economia se caracteriza pela formação de redes virtuais, responsáveis pela constituição de estratos, de perfis e de hábitos sociais semelhantes nos mais diferenciados países. Essas novas formas de interação criam novas formas de sociabilidade e novas identidades, mediadas pelas redes midiáticas globalizadas.

Em outro registro, ao se referir à era da informação, Castells (2000 p. 17) afirma:

"A revolução da tecnologia da informação e a reestruturação do capitalismo introduziram uma nova forma de sociedade, a sociedade em rede. Essa sociedade é caracterizada pela globalização das atividades econômicas decisivas do ponto de vista estratégico, por sua forma de organização em redes; pela flexibilidade e instabilidade do emprego e pela individualização da mãode-obra. Por uma cultura de virtualidade real construída a partir de um sistema de mídia onipresente, interligado e altamente diversificado". 
Segundo o autor, esta sociedade está ligada por redes telemáticas que crescem de forma exponencial. Essas redes configuram a nova morfologia social, modificando os resultados dos processos produtivos e da experiência humana.

Em outra perspectiva, sublinha Becerra (2003, p.11), a sociedade da informação abre-se para:

"La posibilidad de digitalizar toda fuente de información y de procesarla, almacenarla y distribuirla por diferentes medios, la potencialidad de combinación de textos, imágenes y sonidos, la interconexión planetaria mediante redes de información y comunicación, son el escenario detonador de esperanzas que, al no anclarse en las condiciones objetivas de acceso, suelen ser desaforadas.. La convergencia de industrias info-comunicacionales que tuvieron desarrollos tradicionalmente divergentes convocan a imaginar un mundo transparente, inmaterial, amigable, flexible y dinámico" (Becerra, 2003).

Conforme tese sustentada pelo autor, a emergência de um novo modelo de desenvolvimento não exclui as tensões e os conflitos que dele advêm. O impacto que as tecnologias aludidas trazem é distinto para cada sociedade, havendo a possibilidade da coexistência de diferentes modelos de sociedade de informação, como coexistem diferentes modelos de sociedade industrial. Assim, em cada campo ou área, as tecnologias de informação e comunicação são sentidas, em seus efeitos, de forma diferenciada.

Diante desse cenário, em que múltiplas transformações se processam, inclusive nos ambientes e nas práticas profissionais, procurou-se verificar que modificações foram introduzidas no comportamento dos bibliotecários que atuam em bibliotecas universitárias públicas e privadas, a partir do emprego das tecnologias de informação e comunicação. Como elas são percebidas por esses profissionais? Houve mudanças nas relações entre os bibliotecários e os usuários? Elas trouxeram novas formas de sociabilidade? Nesse quadro, que novas posturas são exigidas desses profissionais?

A metodologia utilizada possui uma abordagem quantitativa e qualitativa. O presente estudo* foi realizado junto aos bibliotecários que atuam em bibliotecas universitárias na rede pública e privada do município de Porto Alegre-RS. A amostra foi composta por 22 bibliotecários, sendo que destes 16 atuam em

\footnotetext{
** Este estudo é parte de uma pesquisa, em andamento, junto ao Departamento de Ciências da Informação/Fabico/UFRGS, intitulada "Entre o tradicional e o virtual: novas sociabilidades nas bibliotecas universitárias” iniciada em 2002.
}

bibliotecas universitárias públicas e seis em bibliotecas universitárias privadas. Da rede pública ${ }^{2}$, foram consideradas a Fundação Faculdade Federal de Ciências Médicas de Porto Alegre (FFFCMPA), que possui uma biblioteca com uma bibliotecária, e a Universidade Federal do Rio Grande do Sul (UFRGS), que possui 32 bibliotecas setoriais e uma central. Em cada uma delas atuam em média três bibliotecários, correspondendo a um total de 99 profissionais. Da rede privada ${ }^{3}$, foram consideradas a Pontifícia Universidade Católica do Rio Grande do Sul (PUCRS), que possui uma biblioteca central e três setoriais, a Centro Universitário Ritter dos Reis (UniRitter), que possui uma biblioteca, e a Faculdades Porto-Alegrenses (Fapa), que possui uma biblioteca central. A primeira conta com 20 bibliotecários, e as outras, com dois em cada uma delas. Todas as bibliotecas pesquisadas estão automatizadas.

Os sujeitos do estudo - os bibliotecários que atuam nestas unidades de ensino superior - são todos do sexo feminino, pertencem a uma faixa etária média de 45,7 anos na rede pública e 40,8 anos na rede privada. Observou-se que o fato de os profissionais pertencerem à rede pública ou privada não alterou significativamente a percepção no modo de ver a interferência do uso das tecnologias de informação e comunicação. Entretanto, a variável idade dos bibliotecários contribuiu na forma de interpretar as interferências do uso das tecnologias. Algumas narrativas, adiante, evidenciam esta diferença.

O instrumento de coleta dos dados utilizado foi a técnica de entrevista realizada durante os meses de setembro, outubro e novembro de 2002. Os dados quantitativos serviram para descrever o universo analisado. As variáveis como idade, sexo, entre outras, serviram para verificar quantitativamente o percentual de bibliotecários que percebe a interferência das tecnologias de informação e comunicação em seus ambientes de trabalho, no uso da comunicação direta entre bibliotecários e usuários e na autonomia dos usuários. Como o estudo das percepções envolve elementos intersubjetivos, foi necessário buscar apoio em dados qualitativos. A formulação de questões abertas nas entrevistas tornou possível captar uma série de informações significativas que revelaram o conteúdo aprendido em experiências profissionais da vida cotidiana dos bibliotecários, sobretudo das suas práticas

\footnotetext{
* Mais informações sobre as bibliotecas de cada instituição pública podem ser obtidas acessando os endereços eletrônicos: <http:// www.fffcmpa.tche.br>, 〈http://www.ufrgs.br>.

** Mais informações sobre as bibliotecas de cada instituição privada podem ser obtidas acessando os endereços eletrônicos: <http:// www.pucrs.br>, 〈http://www.ritterdosreis.br>, 〈http://www.fapa.com.br〉.
} 
Tecnologias de informação e comunicação: novas sociabilidades nas bibliotecas universitárias

de trabalho, às quais denominamos narrativas. Elas possibilitaram descrever a trama complexa que envolve o cenário e as suas transformações no mundo do trabalho que esses profissionais estão vivenciando na atualidade, com a introdução e a intensificação do uso das tecnologias de informação e comunicação nas bibliotecas universitárias. As narrativas desvendaram que, por trás das mediações tecnológicas, existem sujeitos sensíveis às mudanças e aos acontecimentos.

Desta forma, o estudo pretende trazer elementos para uma reflexão sobre as novas sociabilidades que envolvem as práticas da profissão do bibliotecário no contexto da sociedade da informação, mostrando que a atuação deste profissional ultrapassa os procedimentos mecânicos e automatizados impostos pelas tecnologias de informação e comunicação. A partir da reflexão crítica, é possível redimensionar políticas e criar estratégias de ação no sentido de viabilizar e implementar propostas de trabalho e, ao mesmo tempo, demonstrar a relevância do trabalho do bibliotecário no contexto social contemporâneo.

\section{TECNOLOGIA, SOCIEDADE E SOCIABILIDADE}

As diversas teorias sobre a sociedade da informação indicam uma transformação radical na estrutura do emprego e das profissões. Conforme Masuda (1982), nesse contexto as tecnologias de informação e comunicação operam como forças propulsoras que modelam as relações sociais, econômicas e políticas, originando um tipo de sociedade diferente. A sua aplicação transforma-se na principal fonte do crescimento econômico, dissolvendo muitos dos problemas dos países menos desenvolvidos.

Nesta ótica, ainda que determinista, percebe-se uma interação entre as tecnologias de informação e comunicação e a sociedade. Tais tecnologias, ao mesmo tempo em que moldam a sociedade, também são moldadas por ela. As tecnologias de informação e comunicação exercem influências profundas na vida cotidiana. Contudo elas não são autônomas e, portanto, não podem ser desvinculadas do contexto social em que foram produzidas.

É difícil prever as múltiplas conseqüências em relação ao emprego, às novas competências e aos novos níveis de qualificação dos trabalhadores com a difusão e aplicação das tecnologias de informação e comunicação. Percebe-se que os impactos sobre serviços interpessoais tradicionais desaparecem com a automação, provocando em decorrência o surgimento de novos serviços.
Uma tendência da sociedade da informação, pelo uso cada vez mais intensivo das tecnologias, é uma reestruturação econômica do emprego e das relações de trabalho. Dentre as novas configurações destas transformações no mundo do trabalho, destacam-se uma organização flexível do trabalho e o aumento do trabalho independente. Conforme sublinha Kovács (2002, p. 37): "A segmentação e flexibilização do trabalho implica a crescente diversidade dos salários laborais e das condições de trabalho, diferenciação e individualização dos trabalhadores e das relações de emprego".

As questões propostas remetem aos processos interacionais e aos estudos de sociabilidade. A sociabilidade e suas diversas formas - relação do eu com o outro e do outro comigo, do eu fora de mim, do eu com o "mesmo" - é uma preocupação antiga na teoria sociológica, desde Augusto Comte, Émile Durkheim, Karl Marx, Max Weber, até os contemporâneos, como Ferdinand Tönnies, Georg Simmel e Norbert Elias.

Neste estudo, a sociabilidade é entendida a partir do referencial teórico de Simmel, que a define como forma específica do processo geral de sociação. A sociação é constituída pelos impulsos, motivos, interesses e objetivos dos indivíduos. Esse conjunto de interesses e objetivos assume formas e conteúdos diferenciados. Para Simmel (1983, p. 166), a sociação é:

"[...] a forma (realizada de incontáveis maneiras) pela qual os indivíduos se agrupam em unidades que satisfazem seus interesses. Esses interesses, quer sejam sensuais ou ideais, temporários ou duradouros, conscientes ou inconscientes, causais ou teleológicos, formam a base das sociedades humanas".

Assim, o processo de sociação é constituído pelos impulsos dos indivíduos, por interesses, objetivos ou por outros motivos e pelas formas que essas motivações assumem. Conforme o autor (1983, p.166):

"Tudo que está presente nos indivíduos (que são dados concretos e imediatos de qualquer realidade histórica) sob forma de impulso, interesse, propósito, inclinação, estado psíquico, movimento - tudo que está presente neles de maneira a engendrar ou mediar influências, designo como conteúdo, como matéria, por assim dizer, da sociação".

A sociedade é produto dessa sociação entre os indivíduos que interagem entre si e com os outros. As formas de interações se desenvolvem em um determinado contexto social. Por isso, na visão de Simmel, a sociedade caracteriza-se como sendo dinâmica, em constante 
transformação e permanente construção. Nesse processo, de múltiplas e variadas formas de interação, os indivíduos, atores socializados, jogam uns com os outros, contra os outros e contra si mesmo.

Segundo Simmel (1983, p.168), "os sociados sentem que a formação de uma sociedade como tal é um valor; são impelidos para essa forma de existência." Assim, necessidades e interesses específicos fazem com que os seres humanos se unam em forma de associações econômicas, religiosas, profissionais e outras. Essas sociações produzem um sentimento, entre seus membros, de "estarem juntos", e a satisfação derivada disso é o que agrega os indivíduos a formar um agrupamento.

A vida em sociedade é um constante fazer, desfazer e refazer, repetindo uma série de formas de convivência e relações de aproximação e de separação, de ações e reações recíprocas entre os indivíduos, de consenso e conflito, de competição, dominação-subordinação, comuns ao jogo da sociabilidade. Essa característica dos homens, de poder associar e dissociar, reforça a idéia da impossibilidade de concretização das "formas puras" e o da inevitabilidade da relação entre os opostos (Simmel, 1996).

Estudos recentes (Lemos, 2001; Sá, 2001) mostram como na sociedade contemporânea configuram-se as novas formas de sociabilidade emergentes a partir das inovações e possibilidades tecnológicas. Neste contexto, em que o fluxo constante das trocas de informações se efetiva pelos meios comunicacionais, torna-se possível a criação de vínculos sociais nas comunidades virtuais. As novas "convivências" advindas da mediação tecnológica têm ampliado a rede de relações entre as pessoas e construído laços afetivos entre elas. O uso das ferramentas disponíveis na Internet abriu a possibilidade de as pessoas se "conhecerem" e estabelecerem relacionamentos sem qualquer contato físico anterior. Essa prática, cada vez mais comum, vem modificando os hábitos, os comportamentos, tornando mais complexas as formas de interação social entre os indivíduos e produzindo novas formas de sociabilidade entre eles.

A sociabilidade, neste estudo, é definida a partir da constituição dos papéis sociais instituídos, ou seja, o desenvolvimento das práticas profissionais dos bibliotecários e o estabelecimento do jogo das relações entre os bibliotecários e os usuários em unidades de informação universitárias. No período em que as bibliotecas possuíam os registros das informações predominantemente em suportes impressos, a sociabilidade entre os bibliotecários e os usuários era marcada pela interação face a face e pela comunicação oral.
Hoje, com a introdução da informação em suportes eletrônicos no acervo das referidas unidades de informação e de tecnologias para acessá-la, abriu-se a possibilidade de consultas a bases de dados on-line.. As trocas de mensagens por meio do correio eletrônico e a participação em videoconferências, entre outros recursos, intensificaram seu uso. A automação das bibliotecas e, conseqüentemente, dos serviços prestados aos usuários, que implicam o uso cada vez mais constante das tecnologias de informação e comunicação, fez com que a sociabilidade entre os atores envolvidos se modificasse substancialmente. A máquina passou a realizar o processo de mediação entre os agentes profissionais, responsáveis pelos serviços de organização, busca e recuperação da informação, e os seus usuários, tornando tais processos mais dinâmicos.

As tecnologias de informação e comunicação, ao permitir a manipulação de diferentes mídias (texto, imagem e som), possibilitam o estabelecimento de "[...] uma relação mais interativa entre o sujeito cognoscente e o conhecimento" (Ferreira, 2003, p. 38). O emprego de tais tecnologias, sem dúvida, trouxe maior rapidez no acesso e transferência da informação em escala mundial. Diante desse contexto, uma questão se impõe: essa mediação tecnológica trouxe maior interação entre os usuários e bibliotecários?

Hoje, o ciberespaço constitui a nova fonte de construção das recentes formas de sociabilidade, possibilitando a comunicação e a disseminação da informação de maneira instantânea. Segundo Giddens (1991), esse processo faz com que haja um desencaixe dos sistemas sociais, ou seja, deslocamento das relações sociais de contextos locais de interação e sua reestruturação por meio de extensões indefinidas de tempo-espaço. $O$ tempo e o espaço já não constituem mais barreiras para que se estabeleçam a comunicação e a troca de informações entre bibliotecários e usuários. Nesse processo, a relação entre as partes é marcada por um jogo - ou entrecruzamentos - que inclui tanto as formas "tradicionais" de sociabilidade quanto as formas "modernas", o que costuma conduzir a relacionamentos tensos, conflituosos e, por vezes, contraditórios.

Tradicionalmente, as práticas dos bibliotecários estiveram alicerçadas na organização e no tratamento técnico das informações em suportes impressos, localizados em centros de documentação e bibliotecas. Além disso, o lugar físico - a biblioteca - e os processos interativos deste profissional com os usuários da informação permitiram que se constituísse a identidade do bibliotecário, competências plenamente consolidadas e regulamentadas pelos estatutos da profissão. 
Tecnologias de informação e comunicação: novas sociabilidades nas bibliotecas universitárias

O avanço das tecnologias de informação e comunicação e suas aplicações em diversas áreas, inclusive nas bibliotecas, possibilitou uma relação direta e interativa dos usuários da informação, tornando-os mais autônomos em relação aos serviços mediados pelos bibliotecários no processo de busca da informação.

A introdução das tecnologias altera as relações dos bibliotecários e as suas práticas, trazendo mudanças na forma de sociabilidade e modificando o perfil deste profissional. Essas transformações fazem com que se reestruture ou se crie uma nova identidade coletiva do profissional. As mudanças tecnológicas e as novas sociabilidades acarretam uma nova forma de articulação, relação e apreensão do conhecimento destes profissionais.

Entretanto, esse processo não é linear. Envolve uma complexidade de elementos e conflitos de diversas ordens. O redimensionamento dos papéis tradicionais no campo profissional e a desterritorialização do espaço físico na biblioteca no ciberespaço geram conflitos, desde a constituição da subjetividade deste profissional, até conflitos de competências com outras profissões. A percepção das formas interativas e a sociabilidade podem nortear o bibliotecário em direção a uma prática que auxilie na construção da auto-imagem e da sua imagem perante os outros.

\section{BIBLIOTECAS UNIVERSITÁRIAS MUNDO CONTEMPORÂNEO}

NO

As bibliotecas como instituições sociais são partes integrantes da sociedade. Como tais, também acompanham os processos de desenvolvimento econômico, social e tecnológico. No mundo contemporâneo, as bibliotecas passaram a utilizar técnicas e processos automatizados e, amparadas pelo conhecimento científico, começaram a dar um tratamento diferente em relação ao armazenamento, registro, disseminação e recuperação da informação.

A profissão de bibliotecário e sua regulamentação nasceram tendo como cenário o processo de racionalização, em que as organizações ou instituições adquirem um papel fundamental no desenvolvimento do processo produtivo. A eficiência e eficácia, nesse contexto, são as palavras-chave. Todos esses aparatos conhecidos hoje, que têm ainda muito sentido e estão, segundo alguns, com os dias contados, são denominados bibliotecas "tradicionais". São aquelas que possuem a maioria do acervo constituído de documentos em suporte de papel (Cunha, 1999).

Ci. Inf., Brasília, v. 33, n. 1, p. 117-125, jan./abril 2004
Tais unidades de informação encontram-se em locais físicos definidos, sendo que seus catálogos são em papel e seus serviços não são automatizados. A figura do bibliotecário está sempre presente no ambiente da biblioteca tradicional. As relações entre usuários e bibliotecários são amplas e visíveis ao olho humano.

As bibliotecas tradicionais, bem ou mal, cumpriram e vêm cumprindo o seu papel. Como organização, elas foram capazes de criar sociabilidades, ou, pelo menos, referendaram tipos de sociabilidade definidos historicamente. Sobre seu futuro, afirmam Drabenstott \& Burman (1997) que, daqui a 20 ou 50 anos, elas terão as coleções deterioradas, novas edificações serão necessárias, novas funções serão atribuídas aos bibliotecários, coleções de valor histórico deverão ir para museus e o restante do acervo será reciclado.

O futuro é incerto, porém é notável que estamos diante de uma realidade de "transição" entre os procedimentos das práticas da profissão consideradas "tradicionais”, que tinham por base o registro das inscrições em suportes impressos em papel e a constituição de novas práticas "modernas", alicerçadas no uso das tecnologias de informação e comunicação. A utilização dessas tecnologias possibilita o rápido acesso à informação e também o uso simultâneo de um mesmo documento. Tais procedimentos, baseados em processos interativos virtuais, constituem o sustentáculo da trama que forma o tecido da cibercultura.

As conjecturas sobre o futuro alertam que, cada vez mais, serão utilizadas as tecnologias de informação e comunicação em todas as áreas da vida social. Nas bibliotecas e centros de informação, não será diferente. Conforme aponta Lancaster (1994), o uso dos computadores nas bibliotecas permitiu que várias operações internas fossem automatizadas, tornando o acesso às fontes da informação em formato eletrônico, mais acessível aos usuários. Segundo o autor, isso leva a um novo conceito de biblioteca. O sistema eletrônico trouxe consigo vantagens como acessibilidade, seletividade e rapidez na disseminação da informação: "[...] a transição do papel para sistemas eletrônicos deve ser olhada como parte de um processo normal e previsível" (Lancaster, 1994, p. 16). Este sonho pregado por alguns autores biblioteca virtual, biblioteca do futuro, biblioteca sem paredes localizada no ciberespaço - já começa a dar seus primeiros sinais. "Em 2010, quase a totalidade, se não a totalidade das bibliotecas universitárias, estará automatizada, e muitas serão totalmente digitais” (Cunha, 2000, p. 75). A automação é pré-requisito para 
a otimização dos processos e serviços desenvolvidos pelas bibliotecas, uma vez que ela beneficia o fornecimento de informações de maneira mais veloz aos usuários.

As bibliotecas universitárias brasileiras enquadram-se nesta nova configuração que as bibliotecas assumem no contexto atual. Localizadas nas universidades e centros da produção técnico-científica, as bibliotecas universitárias são responsáveis pelo tratamento, armazenamento e disponibilização do acervo das mesmas e devem estar de acordo com os objetivos de suas instituições mantenedoras. Entretanto, como a implantação das tecnologias de informação e comunicação ainda é recente, essas unidades de informação disponibilizam as informações armazenadas em suporte impresso e em suporte eletrônico, dando um caráter "híbrido" ao seu acervo.

Ao empregar as tecnologias de informação e comunicação, as bibliotecas universitárias criaram novos serviços e aperfeiçoaram os já oferecidos. Nas bibliotecas pesquisadas foram encontrados serviços de referência on-line, acesso a bases de dados gerais e especializadas, entre a prestação de outros serviços. Além disso, tais unidades de informação disponibilizam a informação nos diferentes suportes (impresso e eletrônico), possuem o sistema de catálogo on-line, e algumas mantêm paralelamente o tradicional catálogo de fichas, porém este instrumento não é mais atualizado. Elas realizam os serviços de processamento técnico da informação, como classificação, catalogação e indexação. Os materiais são adquiridos mediante compra, doação ou permuta.

Hoje, percebe-se que as bibliotecas universitárias caminham para uma dependência quase total do emprego das tecnologias de informação e comunicação e dos processos automatizados inerentes a essas tecnologias. Diante desta realidade, é quase impossível imaginar as tarefas de rotina realizadas em uma biblioteca sem o auxílio de processos automatizados, que possibilitam a conexão com a rede mundial de computadores em tempo integral.

Desta forma, as bibliotecas universitárias, ao utilizar e incorporar em suas práticas cotidianas as tecnologias de informação e comunicação, alteraram as formas de sociabilidade, implicando o redimensionamento dos papéis sociais dos atores que nela atuam, construindo novas formas de sociabilidade.

\section{O USO DAS TECNOLOGIAS DE INFORMAC̣̃̃O E COMUNICAC̣ÃO NAS BIBLIOTECAS UNIVERSITÁRIAS E AS PERCEPÇÕES DOS BIBLIOTECÁRIOS}

Com o objetivo de captar as percepções dos bibliotecários em relação ao uso das tecnologias de informação e comunicação na constituição das novas formas de sociabilidade entre bibliotecários e usuários, foram analisadas três variáveis: a interferência das tecnologias de informação e comunicação entre as relações do bibliotecário e o usuário; uso da comunicação direta entre bibliotecário e o usuário; o grau de autonomia do usuário em relação ao uso das tecnologias de informação e comunicação.

Em relação à interferência das TICs nas relações entre os bibliotecários e os usuários, 77,3\% dos entrevistados responderam que a tecnologia interfere na sua relação com o usuário e 22,7\% que não há interferência. Dos que percebem a interferência, 70,5\% trabalham em bibliotecas públicas e $29,5 \%$ atuam em bibliotecas privadas.

Quanto à percepção dos bibliotecários em relação à utilização das tecnologias de informação e comunicação e a manutenção da comunicação face a face entre os bibliotecários e os usuários, 54,6\% afirmaram que aumentou a comunicação deste tipo, ocorrendo o mesmo nível de igualdade de 22,7\% entre a diminuição e sem alterações na forma de interação face a face. Esses dados parecem contraditórios, pois o aumento do uso das TICs diminuiria a interação direta (face a face) entre bibliotecários e usuários. Entretanto, conforme a percepção de alguns bibliotecários, esse tipo de interação aumentou.

Em relação ao grau de autonomia dos usuários na busca da informação com emprego da tecnologia, 50\% dos bibliotecários percebem que os usuários estão mais autônomos, 22,7\% parcialmente autônomos e 27,3\% não-autônomos. Na percepção dos bibliotecários, as mudanças introduzidas pelo uso das tecnologias de informação e comunicação no seu ambiente de trabalho e nas relações com os usuários trouxeram maior autonomia na busca das informações. As tecnologias de informação e comunicação possibilitaram uma mudança de comportamento dos usuários em relação ao uso da biblioteca e das fontes de informação. Visto que a maior parte dos usuários já domina as ferramentas de informática, especialmente a Internet, quando ingressam nas instituições de ensino, eles apresentam certo grau de autonomia em relação ao uso das tecnologias referidas. 
Tecnologias de informação e comunicação: novas sociabilidades nas bibliotecas universitárias

Entretanto, os dados quantitativos não foram suficientes para verificar as modificações nas relações entre bibliotecários e usuários a partir do uso das tecnologias, pois elas envolvem um conjunto de significações que fazem parte do processo de elaboração dos sujeitos envolvidos nestas interações sociais. Na tentativa de evidenciar a complexidade destas relações, apoiamo-nos em algumas narrativas dos bibliotecários. Elas expressam a autonomia dos usuários quanto à busca de informações e às mudanças ocorridas na rotina do trabalho dos bibliotecários em relação ao processo de organização e quanto ao tratamento da informação:

"A primeira mudança que percebo é em relação ao aluno. Ele antigamente dependia muito de nossa ajuda para localizar o livro na estante. Hoje se dá um treinamento no início, se ensina uma vez, e eles sozinhos se acham na biblioteca. Às vezes, solicitam ajuda quanto ao assunto (Helena, 41 anos, biblioteca universitária pública).

"Com a tecnologia ficou melhor, mais dinâmico, há mais recursos. Quando não sabemos a resposta, entramos em contato com colegas e respondemos por e-mail (Maria, 46 anos, biblioteca universitária pública).

"Em relação ao usuário, ensinava-se a usar fichas, e agora tem de ensinar a usar catálogo. A biblioteca atende a usuários de áreas distintas, sendo que alguns têm de ensinar a clicar o mouse (eles têm medo do computador). O computador exige mais trabalho, para alguns é preciso ensinar a usar o computador, antes de ensinar o catálogo (Joice, 47 anos, biblioteca universitária pública).

"Em relação ao processamento técnico, há facilidade maior de inserir dados na base, em função de ter acesso à importação de registros de outras bibliotecas, estar conectado à rede, ter acesso a bibliotecas de outros países e a uma série de informações autorizadas. Antes se preenchia um formulário à mão e outra pessoa digitava, que não o bibliotecário. Atualmente, entramos diretamente com os dados no computador" (Maristela, 39 anos, biblioteca universitária pública).

Percebe-se pelas narrativas que novas atividades estão sendo incorporadas no exercício da profissão do bibliotecário, enquanto outras estão sendo abandonadas. Dentre as novas atividades, destacam-se algumas, como importação de dados, transferência de informação para o usuário por meio da rede e educação do usuário orientada também para as fontes de informação disponíveis on-line. Entretanto, o ponto forte é a automação das bibliotecas. Conforme previsão de Cunha (1999), em 2010 quase a totalidade das bibliotecas universitárias estará automatizada. Neste cenário, o fato de o suporte impresso estar sendo "substituído" pelo eletrônico não significa a exclusão total do primeiro, mas a coexistência de ambos.

As narrativas a seguir demonstram a complexidade que as tecnologias trouxeram na constituição das novas práticas profissionais e a modificação no modo de interagir entre bibliotecários e usuários.

"O bibliotecário passou a se dedicar mais ao serviço interno e menos ao serviço ao público. O principal fator de mudança foi o computador" (Joana, 61 anos, biblioteca universitária pública).

"Agora trabalho quase o tempo inteiro com computador, comunico-me muito com o usuário de outras bibliotecas por meio do computador. Meu trabalho depende muito do computador e acesso à rede. Hoje o trabalho do bibliotecário é extremamente dependente do computador, principalmente de bibliotecários de bibliotecas universitárias e especializadas" (Eduarda, 43 anos, biblioteca universitária pública).

"Acho que a relação ficou mais informal, mas não houve distanciamento. Antigamente o usuário pedia o livro e ia para casa. Hoje acabam questionando mais, buscam mais informações. O treinamento do usuário é feito de outra maneira. Acabamos tendo mais contato com o usuário. Antes, a relação era mais fria" (Rosa, 53 anos, biblioteca universitária pública).

"A relação mudou para melhor. É como um desafio, pois com a evolução das tecnologias, temos que estar atentos às mudanças" (Renata, 55 anos, biblioteca universitária privada).

"Com o uso das tecnologias, houve maior interação entre usuários, bibliotecários e auxiliares. Os usuários procuram ajuda não só no ambiente físico, mas por e-mail" (Maria, 46 anos, biblioteca universitária privada).

As narrativas evidenciam que o uso das tecnologias modifica as interações entre os bibliotecários e os usuários. Surge uma nova forma de comunicação, mediada pelos meios tecnológicos, proporcionando o dinamismo e a rapidez na busca e nas trocas de informações, o que não implica, necessariamente, um distanciamento entre os atores envolvidos. Nesse sentido, confirma-se a proposição de Masuda (1982), quando ele afirma que as tecnologias de informação e comunicação causam impactos na vida cotidiana e atuam como forças propulsoras no processo de transformação das relações sociais. Esse processo analisado é por Giddens (1991) como responsável pelo "desencaixe" dos sistemas sociais. 
Além disso, o emprego das tecnologias de informação e comunicação exige dos profissionais alto nível de especialização e faz com que os mesmos desempenhem uma educação continuada para atender às necessidades de suas práticas profissionais.

Porém, alguns bibliotecários não percebem as mudanças trazidas pela tecnologia. Afirmam que o contato com o usuário é realizado da mesma maneira que no passado, antes do uso das tecnologias de informação e comunicação.

"Não vejo mudanças propriamente com os usuários. Mudou um pouco porque antes se ensinava ou orientava o usuário como se movimentar exclusivamente no mundo do papel, hoje a gente mostra como obter informações de outras fontes. Não houve afastamento do usuário da biblioteca ou do bibliotecário, acho que a relação permaneceu" (Vânia, 40 anos, biblioteca universitária pública).

"Não vejo em que a tecnologia mude o relacionamento com o usuário. A gente pode ter contato com o usuário por e-mail, ele acessando a página na Internet, mas o usuário acaba tendo que vir à biblioteca. Não vejo mudanças" (Vânia, 40 anos, biblioteca universitária pública).

"Acho que o comportamento não se modificou. Eles precisam, como antes ocorria com o papel, de um aconselhamento, de saber como funciona o processo. $\mathrm{O}$ treinamento ainda é dado. O contato ainda continua sendo como era antes, nos perguntam no bar, no corredor, até em casa já me telefonaram" (Helena, 41 anos, biblioteca universitária pública).

Para a minoria dos bibliotecários entrevistados, as relações entre o uso das tecnologias e as novas práticas da profissão parecem não estar associadas. Entretanto, o ensino, a comunicação e a disseminação das informações para os usuários são mediados por processos que utilizam as tecnologias de informação e comunicação. Conforme apontam Lemos (2001) e Sá (2001), a mediação tecnológica faz emergir novas formas de sociabilidade, abrindo novas possibilidades de as pessoas estabelecerem novos relacionamentos.

As mesmas tecnologias de informação e comunicação que possibilitam o acesso e o uso das fontes de informação disponíveis na rede de computadores trouxeram, também, algumas tensões no relacionamento entre os bibliotecários e os usuários. Essas "zonas de conflito" são percebidas pelos bibliotecários, que se expressam nas seguintes narrativas:
"O que modificou é o relacionamento com nosso leitor, porque quando comecei havia um contato maior dos leitores com o bibliotecário, hoje, ele está muito distante e, às vezes, hostil" (Joana, 61 anos, biblioteca universitária pública).

"Os usuários não se submetem às nossas orientações, por exemplo, avisos de não beber, comer e usar celular, eles nos desafiam e acaba-se tendo problemas com usuários. Isso antigamente não existia, mas não é somente o caso da nossa biblioteca, são os novos tempos" (Joana, 61 anos, biblioteca universitária pública).

"Eu sou o carrasco de todos, isso é porque eles não podem acessar a Internet, não podem fazer isso ou aquilo, somos vistas como bruxas. Eles acham que a biblioteca é a casa deles, que podem entrar com água, celular e fazendo barulho. Mas claro que existem aqueles que são educados também. O agradecimento é raro" (Rita, 37 anos, biblioteca universitária pública).

"A tecnologia trouxe benefícios, mas a partir do momento que não há equipamentos para o usuário utilizar, cria-se um atrito entre bibliotecários e usuários. O bibliotecário vira um carrasco por não deixar ver e-mail e acessar a Internet" (Rita, 37 anos, biblioteca universitária pública).

O conflito, como afirma Simmel (1983), é uma forma de sociação tão necessário à vida em grupo quanto o consenso. Na visão do autor, o conflito é uma condição para a própria manutenção da vida em sociedade, por isso ele é parte do jogo da sociabilidade. No processo de interação social, no ambiente das bibliotecas universitárias, as relações que se estabelecem entre os bibliotecários e os usuários demonstram que o uso das tecnologias não faz desaparecer os conflitos. $\mathrm{O}$ que se observa é a manutenção das relações de poder fundamentadas na constituição dos papéis sociais dos sujeitos de tal forma que, no processo interacional, o bibliotecário conserva seu domínio sobre o usuário baseado nas competências atribuídas socialmente.

\section{À GUISA DE CONCLUSÃO}

O contexto da sociedade da informação que se vislumbra, em que a mediação dos significados compartilhados passa a ser realizada mediante o auxílio do computador, com a utilização das tecnologias de informação e comunicação, gera diferentes impactos, entre os quais uma nova forma de sociabilidade. Ela se caracteriza pelas transformações nos processos interacionais entre os próprios bibliotecários em seus ambientes de trabalho, envolvendo novas práticas profissionais em relação às formas de gerenciamento da informação e dos serviços 
Tecnologias de informação e comunicação: novas sociabilidades nas bibliotecas universitárias

prestados e na interação com os usuários. Além disso, interfere na construção, na apreensão e na articulação do conhecimento na sociedade contemporânea.

À medida que os bibliotecários passam a empregar as tecnologias de informação e comunicação, de forma ampliada, tais ferramentas passam a se constituir elementos de sua prática profissional. A amplitude do seu uso passa a interferir na relação com os usuários da informação, bem como nas formas de interpretar suas práticas, levando o profissional a construir novos modos de subjetivação de sua profissão e suas práticas. Assim, poderíamos pensar a relação entre tecnologia e sociabilidade, percebida a partir da prática profissional, como responsável pela construção da identidade social dos bibliotecários no contexto atual?

Na visão dos bibliotecários pesquisados, o emprego das tecnologias de informação e comunicação nas bibliotecas universitárias torna os usuários mais autônomos em relação à busca de informações em suas fontes. Entretanto, essa autonomia dos usuários não implica, necessariamente, uma substituição das formas "tradicionais" de sociabilidade, nas relações face a face e na comunicação oral. Esses processos interativos entre bibliotecários e usuários podem, inclusive, intensificar-se. Assim, por meio das narrativas, percebeu-se que há coexistência entre as formas "tradicionais" de sociabilidade e as formas "modernas", denominadas sociabilidades virtuais.

Por longo tempo, a imagem dos bibliotecários na sociedade permaneceu atrelada ao lugar físico da biblioteca e à ordenação dos livros. De certa forma, sua imagem ainda continua colada a eles. Difícil prever por quanto tempo essa imagem vai perdurar. Todavia, com a utilização mais intensiva das tecnologias de informação e comunicação, o conseqüente aumento dos suportes eletrônicos da informação, a criação das bibliotecas digitais e as novas formas de sociabilidade, a imagem desses profissionais, aos poucos, apresenta os primeiros sinais de rompimento de identificação com o bibliotecário "tradicional”. Nesse processo, surge o conflito entre as imagens que se justapõem e contrapõem. Como no jogo das sociabilidades, o imaginário social faz, desfaz e refaz, fazendo emergir uma nova imagem e identidade profissional. Nesse jogo, estaria nascendo um novo profissional?
As conclusões deste artigo não pretendem ser extensivas em sua abrangência. Isto é, elas não são generalizáveis para todas as situações e contextos sociais. Mesmo porque elas refletem resultados parciais de uma pesquisa em andamento. Não são proposições fechadas, elas estão abertas ao debate e ao diálogo. Elas apontam inquietações, reflexões, possíveis caminhos que, talvez, possam servir de ponto de partida para outros estudos a respeito do tema em questão.

Artigo recebido em 28-01-2004 e aceito para publicação em 24-04-2004.

\section{REFERENNCIAS}

BECERRA, Martín. Sociedad de la información: proyecto, convergencia y divergencia. Buenos Aires : Grupo Editorial Norma, 2003.

CASTELLS, Manuel. A era da informação: economia, sociedade e cultura. In: Terra, 2000. v. 2 .

CUNHA, Murilo Bastos da. Construindo o futuro: a biblioteca universitária em 2010. Ciência da Informação, Brasília, v. 29, n. 1, p. 71-89, jan./abr. 2000.

Desafios na construção da biblioteca digital. Ciência da Informação, Brasília, v. 28, n. 3, p. 255-266, set./dez. 1999.

DRABENSTOTT, Karen. M.; BURMAN, Celeste M. Revisão analítica da biblioteca do futuro. Ciência da Informação, Brasília, v. 26, n. 2, p. 180-194, maio/ago. 1997.

EISENBERG, José; CEPIK, Marco. Internet e política: teoria e prática da democracia eletrônica. Belo Horizonte : Editora da UFMG, 2002.

FERREIRA, Rubens da Silva. A sociedade da informação no Brasil: um ensaio sobre os desafios do Estado. Ciência da Informação, Brasília, v. 32, n. 1, p. 36-41, jan/abr. 2003.

GIDDENS, Anthony. As conseqüências da modernidade. São Paulo : Editora UNESP, 1991.

KOVÁCS, Ilona. As metamorfoses do emprego: ilusões e problemas da sociedade da informação. Oeiras : Celta, 2002.

LANCASTER, F. W. Ameaça ou oportunidade? Revista da Escola de Biblioteconomia da UFMG, Belo Horizonte, v. 23, n. 1, p. 7-27, jan./ jun. 1994.

LEMOS, André; PALACIOS, Marcos. (Org.). As janelas do ciberespaço. Porto Alegre : Sulina, 2001.

MASUDA, Yoneji. A sociedade da informação como sociedade pós-Industrial. Rio de Janeiro : Ed. Rio, 1982.

SÁ, Simone Pereira de. Utopias comunais em rede: discutindo a noção de comunidade virtual. Fronteiras: estudos midiáticos, São Leopoldo, v. 3, n. 2, p. 131-149, dez. 2001.

SIMMEL, Georg; MORAES FILHO, Evaristo de. (Org.). Sociologia. São Paulo : Ática, 1983.

A ponte e a porta. Política $\mathcal{E}$ Trabalho, João Pessoa, n. 12, p. 10-14, set. 1996 . 